\title{
Steroid receptor coactivator-3 differentially regulates the inflammatory response in peritoneal macrophages
}

\author{
JUN LI $^{1}$, YING-HAI LIU ${ }^{1}$, SHAN OU $^{1}$, XUE-MEI DAI ${ }^{1}$, JUN-PING WANG $^{2}$ and YONG-PING SU ${ }^{2}$ \\ ${ }^{1}$ Department of Anesthesia, General Hospital of Chengdu Military Command Area, Chengdu, Sichuan 610083; \\ ${ }^{2}$ Institute of Combined Injury of PLA, State Key Laboratory of Trauma, Burn and Combined \\ Injury, Third Military Medical University, Chongqing 400038, P.R. China
}

Received September 25, 2011; Accepted January 3, 2012

DOI: $10.3892 / \mathrm{mmr} .2012 .750$

\begin{abstract}
Steroid receptor coactivator-3 (SRC-3) is a transcriptional coactivator that plays an important role in the regulation of cytokine mRNA translation. In the present study, SCR-3 gene knockout mice were used to study the effects of SCR-3 on the regulation of the inflammatory response in peritoneal macrophages induced by lipopolysaccharides (LPS). Peritoneal macrophages (PMs) of SRC-3 $3^{-/}$mice showed a decrease in the release of TNF- $\alpha$, IL- $1 \beta$ and IL-6, and an increase in the release of IL-10. Furthermore, results of RT-PCR also showed that levels of TNF- $\alpha$, IL-1 $\beta$ and IL- 6 mRNA expression were significantly lower, while the level of IL-10 mRNA expression was higher in the SRC- $3^{-/-}$mice, compared to those of wild-type mice, following treatment with LPS ( $p<0.01)$. In addition, western blotting revealed that: i) the extent of reduction of the glucocorticoid receptor in PMs from SRC $-3^{-/}$mice was significantly lower than that in wild-type mice $(\mathrm{p}<0.01)$; ii) the extent of increase of AP-1 in PMS from SRC- $3^{-/}$mice was significantly lower than that in wild-type mice $(\mathrm{p}<0.01)$; iii) the extent of increase of $\mathrm{NF}-\kappa \mathrm{B}$ p65 in $\mathrm{PMs}$ from $\mathrm{SRC}-3^{-/}$mice was significantly higher than that in wild-type mice $(\mathrm{p}<0.01)$. Collectively, our studies revealed that SRC-3 may play a key role in the maintenance of innate immunity. Furthermore, absence of the SRC-3 protein may result in the partial loss of inflammation and phagocytosis barrier function, including suppression of LPS-induced transcriptional activity, release of TNF- $\alpha$, IL- $1 \beta$ and IL- 6 , and obstruction of the function of phagocytes and elimination of bacteria, as well as their production.
\end{abstract}

Correspondence to: Professor Yong-Ping $\mathrm{Su}$ and $\mathrm{Dr}$ Jun-Ping Wang, Institute of Combined Injury of PLA, State Key Laboratory of Trauma, Burn and Combined Injury, Third Military Medical University, 30 Gaotanyan Main Street, Chongqing 400038, P.R. China

E-mail: yongpingsutmmu@yahoo.cn

E-mail: junpingwangtmmu@yahoo.cn

Key words: steroid receptor coactivator-3, peritoneal macrophages, systemic inflammatory response syndrome

\section{Introduction}

The steroid receptor coactivator (SRC) family is composed of SRC-1, SRC-2 and SRC-3. These cofactors interact with nuclear receptors in a ligand-dependent manner and enhance transcriptional activation by the receptor via histone acetylation/methylation and recruitment of additional cofactors (1-3). An indispensable member of the SCR families, SRC-3 belongs to the p160 family of nuclear receptor coactivators that significantly affect physiological function and growth and development, involving cell proliferation, cell migration, cell differentiation, somatic growth, sexual maturation, female reproductive function, vaso-protection and breast cancer (4-6).

Macrophages play an important role between the natural non-specific immune and the specific immune responses. Macrophages promote inflammatory reactions and activation of T lymphocytic cells through secretion of cytokines or antigen processing and presentation, thereby initiating specific immune responses. In addition, the above-mentioned effects of macrophages are induced by different stimuli, such as LPS and cytokines. The ability of macrophages is restricted under normal physiological conditions; however, detrimental effects are induced when the responses to the stimuli of macrophages are altered.

The activation of the inflammatory cascade is significantly involved in the development of resistance mechanism disorders following severe trauma and infection (7). Over-activation of macrophages following severe trauma may induce the synthesis of cytokines (IL- 1, TNF- $\alpha$, IL- 6 and TGF- $\beta$ ), and an increase in RNI and PGE2 $(8,9)$. Subsequently, the level of inflammatory mediators in the body are elevated (10). Finally, systemic inflammatory response syndrome (SIRS) is caused by a local inflammatory response induced by severe trauma and infection that is thought to be mediated by the presence of circulating inflammatory mediators. Therefore, SIRS plays a crucial role in the development of resistance mechanism disorders following severe trauma and infection $(11,12)$. Overactivation of macrophages increases the susceptibility of sepsis after severe trauma and infection, which has been described as a 'two-hit' event (13). The first-hit of severe trauma primarily induces the abnormal reactions in the body, such as the release of inflammatory mediators, and the second hit (such as sepsis) may lead to multiple organ failure and death. 
Table I. Primer sequences used in RT-PCR assay of cytokine mRNA.

\begin{tabular}{lll}
\hline Genes & \multicolumn{1}{c}{ Forward primer sequence } & \multicolumn{1}{c}{ Reverse primer sequence } \\
\hline TNF- $\alpha$ & 5'-CGTGGAACTGGCAGAAGAGG-3' & 5'-GGGCTACAGGCTTGTCACTC-3' \\
IL-1 $\beta$ & 5'-GCATCCAGCTTCAAATCTCAC-3 & 5'-GTTCATCTCGGAGCCTGTAGT-3' \\
IL-6 & 5'-CCTTCTTGGGACTGATGCTG-3' & 5'-GGACTCTGGCTTTGTCTTTC-3' \\
IL-10 & 5'-GCTGGACAACATACTGCTAAC-3' & 5'- TAGACACCTTGGTCTTGGAG-3' \\
$\mathrm{G}_{3} \mathrm{PDH}$ & 5'-ACCACAGTCCATGCCATCAC-3' & 5'-TCCACCACCCTGTTGCTGTA-3' \\
\hline
\end{tabular}

To investigate the effect of SCR-3 in the development of SIRS, we studied the regulation of the inflammatory response by SCR-3 in peritoneal macrophages (PMs) based on the primary cultures of PMs.

\section{Materials and methods}

Animals. SRC-3 knockout mice (SRC-3- mice) were obtained as previously described (14), and wild-type (SRC- $3^{+/+}$mice) littermates served as control (both were of a C57/129 mouse background). All experiments were performed using 3-monthold female mice (20-25 g), that were acclimatized for 1 week prior to the initiation of any procedures. All our experimental protocols were approved by the Animal Care and Use Committee of our institute.

Peritoneal macrophage preparation. Thioglycollate-elicited peritoneal exudate cells were obtained from 3-month-old C57/129 female wild-type and SRC-3 ${ }^{-/}$mice following intraperitoneal injection of $1 \mathrm{ml}$ Brewer thioglycollate broth $(4.05 \mathrm{~g} / 100 \mathrm{ml}$; Sigma-Aldrich, USA) and lavage of the peritoneal cavity with $5 \mathrm{ml}$ of medium 3-4 days later. The cells were washed twice and resuspended in RPMI-1640 containing 10\% heat-inactivated fetal calf serum (FCS; Hyclone, USA), penicillin (100 IU/ml) and streptomycin (100 g/ml; RPMI-FCS). Macrophages were isolated from peritoneal exudate cells as described (15). Peritoneal exudate cells were seeded at densities of $5-6 \times 10^{5}$ cells $/ \mathrm{cm}^{2}$ on Teflon-coated Petri dishes $(100 \times 15 \mathrm{~mm})$, and the macrophages were allowed to adhere for $2 \mathrm{~h}$ in a $5 \% \mathrm{CO}_{2}$ humidified atmosphere. The non-adherent cells were removed by washing the dishes twice with $10 \mathrm{ml}$ pre-warmed medium, and the adherent cells were used as PMs.

Measurement of cytokines. Concentrations of TNF- $\alpha$, IL-1 $\beta$, IL-6 and IL-10 in peritoneal fluid were determined using commercial ELISA kits (Jingmei Biotech Co., Ltd., USA), according to the manufacturer's instructions.

RT-PCR assay of cytokine mRNA. Total RNA was prepared from the PMs using Takara reagent (Takara, Dalian, China) according to the manufacturer's instructions and quantified spectrophotometrically. Primer sequences were obtained from the literature or by Primer 5.0 software and were designed as shown in Table I. The PCR reactions for TNF- $\alpha$, IL- $1 \beta$, IL- 6 and IL-10 were carried out for 30, 28, 30 and 30 amplification cycles, respectively $\left[94^{\circ} \mathrm{C} / 30 \mathrm{sec} ; 53^{\circ} \mathrm{C}(\mathrm{TNF}-\alpha), 54^{\circ} \mathrm{C}\right.$ (IL-1 $\beta$ ), $51^{\circ} \mathrm{C}$ (IL-6), $52^{\circ} \mathrm{C}$ (IL-10)/30 sec; $72^{\circ} \mathrm{C} / 60 \mathrm{sec}$, in an RT-PCR system (Eppendorf, Germany). Ten microliters of each PCR product was electrophoresed on a 1.5\% agarose gel and visualized by ethidium bromide staining.

Western blot analysis of glucocorticoid receptor (GR), $N F-\kappa B$, $A P-1$ and IRF-1. PMs were collected, and $80 \mu \mathrm{l}$ M-Per ${ }^{\mathrm{TM}}$ Mammalian protein extraction reagent (Pierce, USA) was added; the mixture was incubated in an ice bank for $10 \mathrm{~min}$. Whole cell lysates were obtained by subsequent centrifugation at $12,000 \mathrm{rpm}$ for $20 \mathrm{~min}$ at $4^{\circ} \mathrm{C}$. Protein concentrations were determined using the Bradford protein assay kit (BioRad, Hercules, CA, USA) with bovine serum albumin (BSA; Hyclone, USA) as standard. Subsequently, $40 \mu \mathrm{g}$ of protein extracts was subjected to $10 \%$ sodium dodecyl sulfatepolyacrylamide gel electrophoresis (SDS-PAGE; Bio-Rad) and transferred to a Protran nitrocellulose membrane. The membrane was incubated with rabbit antibody polyclonal antibody or rabbit anti-Bcl-2 polyclonal antibody (Zhongshan Golden Bridge Biotechnology Co., Zhongshan, China) at $4^{\circ} \mathrm{C}$ overnight, after being blocked with a $10 \%$ BSA solution. The membrane was washed with TBST buffer $(20 \mathrm{mmol} / \mathrm{l}$ Tris- $\mathrm{HCl}$ $\mathrm{pH} 7.4,150 \mathrm{mmol} / 1 \mathrm{NaCl}$ and $0.1 \%$ Tween-20), incubated with a secondary goat anti-rabbit horseradish peroxidase (HRP)conjugated antibody (Zhongshan Golden Bridge Biotechnology Co.) for $2 \mathrm{~h}$ at room temperature, and finally detected using the DAB kit (Sigma-Aldrich). $\beta$-actin (Sigma-Aldrich) was used as an internal control for data analysis.

Statistical analysis. All the results are expressed as the means \pm SEM. The statistical significance of differences was analyzed using SPSS software (SPSS for Windows 15.0; SPSS Inc., USA). $\mathrm{P}<0.05$ was indicative of statistical significance.

\section{Results}

Results of ELISA assays. Normally, there is no expression difference in TNF- $\alpha$, IL-1 $\beta$, IL- 6 and IL-10 between SRC- $3^{+/+}$ and SRC $-3^{-1-}$ mice. The concentrations of TNF- $\alpha$, IL- $1 \beta$ and $\mathrm{IL}-6$ in the serum of SRC- $3^{+/+}$and SRC- $3^{-/}$mice were significantly increased at 1 and $4 \mathrm{~h}$ after injection of LPS (i.p., $5 \mathrm{mg} / \mathrm{kg}$ ). However, the concentrations of TNF- $\alpha$, IL-1 $\beta$ and IL-6 in the serum of SRC- $3^{+/+}$mice were significantly higher compared to levels in the SRC- $3^{--}$mice. The IL-10 levels in the SRC $-3^{+/+}$and SRC- $3^{-/}$mice at $1 \mathrm{~h}$ after injection of LPS were not different at $0 \mathrm{~h}$ (normal phase), but they were significantly increased at $4 \mathrm{~h}$ after injection. In addition, the concentration of IL-10 in the serum of SRC-3 ${ }^{-1-}$ mice was significantly higher compared to that in the SRC- $3^{+/+}$mice. The concentration of 
A
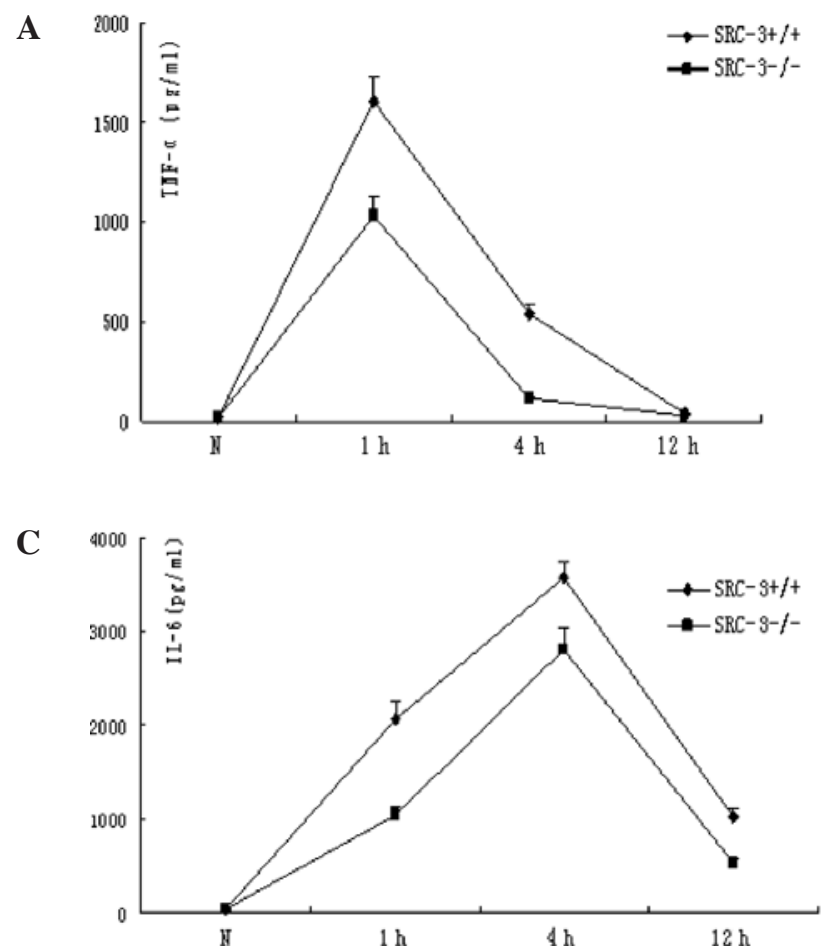

B

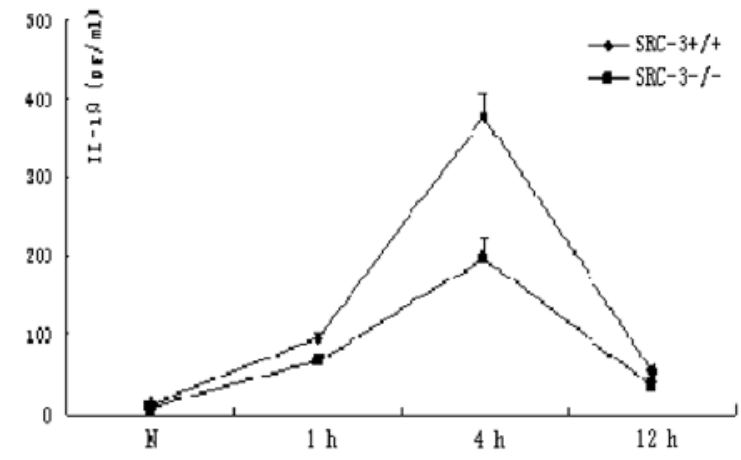

D

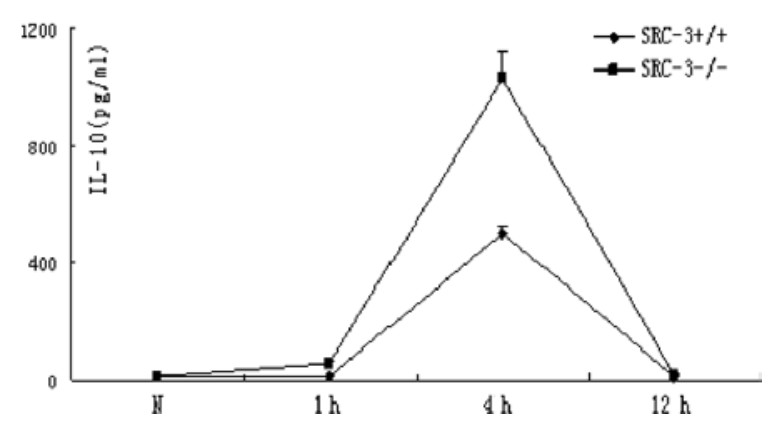

Figure 1. Changes in expression levels of cytokines after injection of LPS. ELISA of (A) TNF- $\alpha$, (B) IL-1 $\beta$, (C) IL-6 and (D) IL-10 in serum from SRC- $3^{+/+}$and SRC-3 ${ }^{-/}$mice at 0, 1, 4 and $12 \mathrm{~h}$ after injection of LPS (i.p., $5 \mathrm{mg} / \mathrm{kg}$ ), respectively. Data are expressed as the means \pm SEM per time point ( $\mathrm{n}=5$ ).

IL-6 in the serum of SRC- $3^{+/+}$and SRC- $-3^{-/-}$mice at $12 \mathrm{~h}$ after injection of LPS was markedly higher than that at $0 \mathrm{~h}$ (normal phase), and the IL-6 levels in the SRC- $3^{+/+}$mice were relatively higher than those in the SRC-3 $3^{-/}$mice (Fig. 1).

Results of the RT-PCR analysis of $m R N A$ expression. PMs were cultured in vitro, and stimulated with LPS at the dose of $10 \mu \mathrm{g} / \mathrm{ml}$. Cells were collected $4 \mathrm{~h}$ after LPS treatment, and total RNA was isolated. RT-PCR analysis of TNF- $\alpha$ mRNA was then performed (Fig. 2A, right panels). Under normal conditions $(0 \mathrm{~h})$, there was no significant difference in TNF- $\alpha$ mRNA expression in the PMs between the $\mathrm{SRC}-3^{+/+}$and SRC $-3^{-/-}$mice. However, the TNF- $\alpha$ mRNA expression of both groups was significantly increased (Fig. 2A, left panels) $4 \mathrm{~h}$ after LPS treatment, and the increase in TNF- $\alpha$ mRNA expression in the PMs from SRC $-3^{+/+}$mice was markedly higher than that of the $\mathrm{SRC}-3^{-/}$mice (136.33 vs. 48.67\%) (Fig. 2A, middle panel).

Results of the RT-PCR analysis of IL- $1 \beta$ mRNA are shown in Fig. 2B. Under normal conditions, no statistical differences in the levels of IL-1 $\beta$ mRNA in PMs were observed between the SRC- $3^{+/+}$and SRC- $3^{-/-}$mice. Following LPS stimulation in vitro, the levels of IL-1 $\beta$ in the two mouse groups at $4 \mathrm{~h}$ were markedly elevated (Fig. $2 \mathrm{~B}$, left panels), and the increase in IL- $1 \beta$ mRNA in the SRC- $3^{+/+}$mice was significantly higher compared to that of the SRC-3 $3^{-/-}$group (101.78 vs. $25.69 \%$; Fig. 2B, middle panel).

Similar results were observed in the RT-PCR analysis of IL-6 mRNA (Fig. 2C). No significant difference in IL-6 mRNA expression was observed between the $\mathrm{SRC}-3^{+/+}$and SRC $-3^{-/}$mice. Following LPS treatment, the IL-6 mRNA expression in the $\mathrm{SRC}-3^{--}$mice was also increased (Fig. $2 \mathrm{C}$, left panels). However, the increase in IL-6 mRNA in the
SRC $-3^{+/+}$mice was significantly higher compared to that of the SRC-3 ${ }^{-/}$group (223.13 vs. $92.16 \%$; Fig. 2C, middle panel).

As shown in Fig. 2D, under normal conditions there was no significant difference in IL-10 mRNA expression in the PMs between the SRC- $3^{+/+}$and SRC- $3^{-/-}$mice. The IL-10 mRNA expression of both groups was markedly increased (Fig. 2D, left panels), however, the increase in IL-10 mRNA expression of SRC- $3^{+/+}$mice was significantly lower compared to that of the $\mathrm{SRC}-3^{-/-}$mice (79.63 vs. 193.86\%) (Fig. 2D, middle panel).

Results of the western blot analysis of GR expression. PMs were cultured in vitro and stimulated with LPS at the dose of $10 \mu \mathrm{g} / \mathrm{ml}$. Cells were collected $4 \mathrm{~h}$ after LPS treatment, and total protein was isolated. Subsequently, SDS-PAGE and western blot analysis for GR were performed with $40 \mu \mathrm{g}$ total protein as isolated. Results of the GR expression analysis are shown in Fig. 3A. Under normal conditions, the expression levels of PM GR in the SRC- $3^{+/+}$mice were not different than those of the $\mathrm{SRC}-3^{-/}$group. However, the expression levels of GR in the PMs in the two groups at $4 \mathrm{~h}$ after LPS stimulation were markedly reduced (Fig. 3A, top panels), and the reduction in the SRC-3 $3^{-/}$group was significantly lower compared to that of the SRC- $3^{+/+}$group (38.2 vs. $60.0 \%$; Fig. $3 \mathrm{~A}$, middle panel).

Results of the western blot analysis of $N F-\kappa B$ p 65 expression. As shown in Fig. 3B, under normal conditions the expression levels of NF- $\kappa \mathrm{B}$ p65 in PMs in the SRC- $3^{+/+}$group were markedly higher compared to those of the SRC- $3^{-/}$group (Fig. 3A, top panels). The expression levels of PM NF- $\mathrm{B}$ p65 in the two groups at $4 \mathrm{~h}$ after LPS stimulation were markedly elevated (Fig. 3A, top panels), but the increase in the SRC-3 $3^{-/}$group was larger compared to that of the $\mathrm{SRC}-3^{+/+}$group (71.0 vs. $45.9 \%$; Fig. 3B, middle panel). 
A

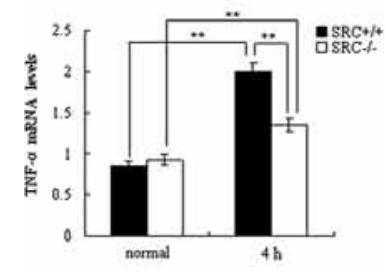

B

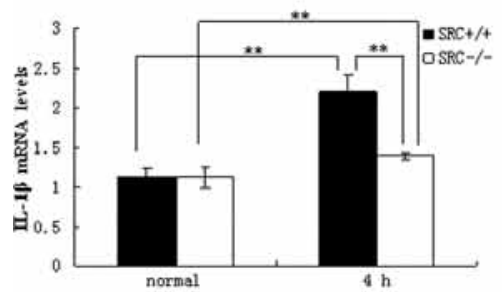

C

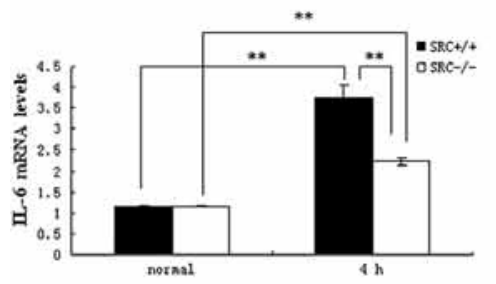

D

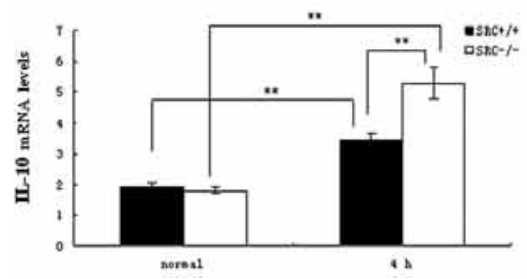

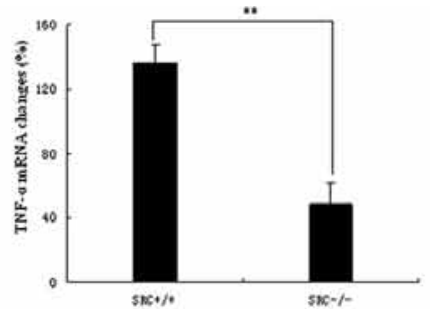
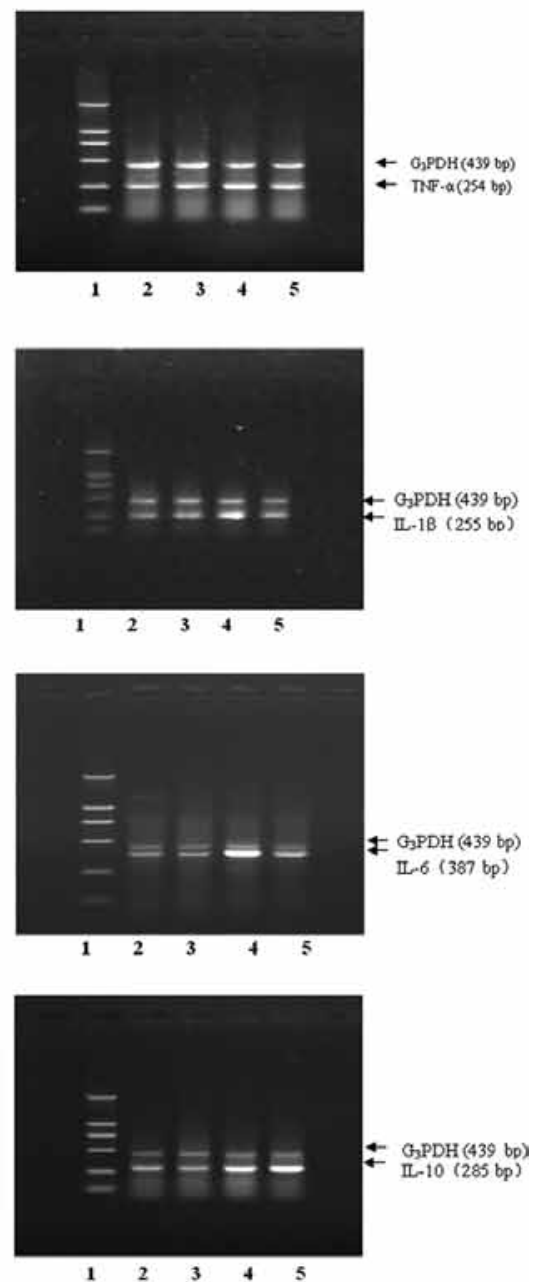

Figure 2. mRNA expression analysis by RT-PCR. mRNA expression of (A) TNF- $\alpha,(\mathrm{B}) \mathrm{IL}-1 \beta$, (C) IL-6 and (D) IL-10 in serum from SRC-3 ${ }^{+/+}$and SRC-3 ${ }^{-/}$mice at $0 \mathrm{~h}$ (normal) and $4 \mathrm{~h}$ after LPS treatment $(10 \mu \mathrm{g} / \mathrm{ml})$, respectively. Analysis of the amplified PCR products by electrophoresis on $1.5 \%$ agarose gels. Lane 1 : DNA marker; the fragment lengths were 2,000, 1,000, 750, 500, 250 and $100 \mathrm{bp}$. Lanes 2 and 4: 0 and $4 \mathrm{~h}$ after injection of SRC-3 ${ }^{+/+}$mice. Lanes 3 and 5: 0 and $4 \mathrm{~h}$ after injection of SRC- $3^{-/}$mice. The fragment lengths of $\mathrm{G}_{3} \mathrm{PDH}, \mathrm{TNF}-\alpha$, IL-1 $\beta$, IL- 6 and IL-10 were $439,254,255,387$ and 285 bp, respectively. Data are expressed as the means \pm SEM per time point $(n=5) .{ }^{* *} \mathrm{p}<0.01$.

Results of the western blot analysis of AP-1 expression. Results of AP-1 expression analysis are presented in Fig. 3C and D. Under normal conditions, the expression levels of c-Jun/c-Fos in PMs in the SRC- $3^{+/+}$group were not different than those of the SRC $-3^{-/-}$group. Following LPS stimulation, the expression levels of c-Jun/c-Fos in PMs in the two groups were markedly elevated at $4 \mathrm{~h}$, but the increase in the SRC- $3^{-/-}$group was lower than that of the SRC- $3^{+/+}$group (9.5 vs. $53.5 \% / 14.8$ vs. $89.6 \%$ ).

\section{Discussion}

As immune effector cells, PMs are the major components of cells in peritoneal fluid. PMs account for $>90 \%$ of abdominal lymphocytes, and play a critical role in the body's immune and inflammatory reactions: anti-infection, antitumor and participation in immune response and immuno-regulation. Abdominal macrophages are normally dormant, but they are activated rapidly by the stimulation of LPS, cytokines and pathogens. Subsequently, cytokines, such as IL-1 $\beta$, TNF- $\alpha$, IL- 6 and TGF- $\beta$, are produced and lead to the activation of the inflammatory cascade and the development of SIRS. In addition, a functional disorder and suppression of macrophages are induced by the over-activation of macrophages; suppression of the body's immune function is accordingly induced. SCR-3 is involved in the activation of the inflammatory cascade reaction, therefore, it is necessary to investigate the changes after SCR-3 deficiency for clarification of the mechanism of immune suppression following development of SIRS.

The main mechanism for inflammation regulation by macrophages is through the release of inflammatory cytokines. Inflammatory cytokines, including TNF- $\alpha$, IL-1 $\beta$, IL-6 and IL-10, are mainly released by macrophages and are important inflammatory mediators for the development of SRIS and immune function disorders. PMs were cultured in vitro and stimulated with LPS at a dose of $10 \mu \mathrm{g} / \mathrm{ml}$. Cells were collected $4 \mathrm{~h}$ after LPS treatment and total RNA was isolated. RT-PCR analysis revealed that the increase in TNF- $\alpha$, IL-1 $\beta$ and IL-6 mRNA in PMs treated with LPS $(10 \mu \mathrm{g} / \mathrm{ml})$ from SRC $-3^{-/-}$mice was significantly lower than that in the $\mathrm{SRC}-3^{+/+}$mice. These results revealed that SCR-3 is involved in the activation of 
A
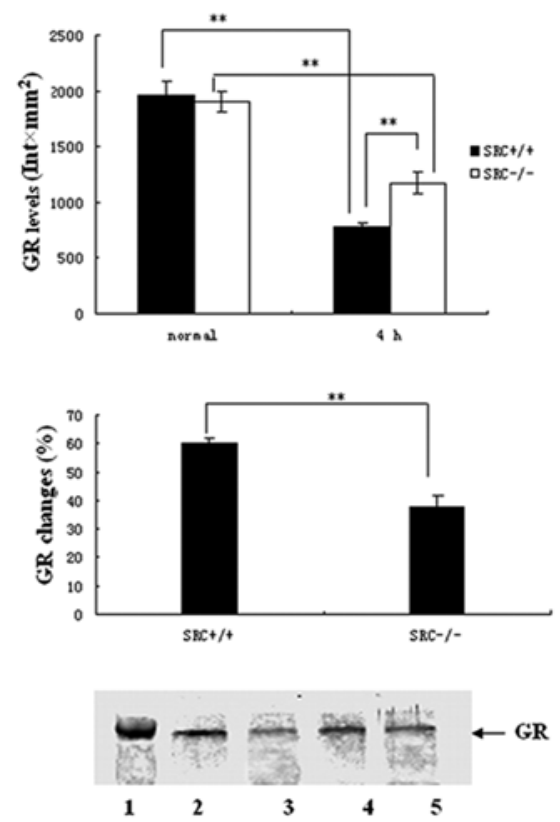

C
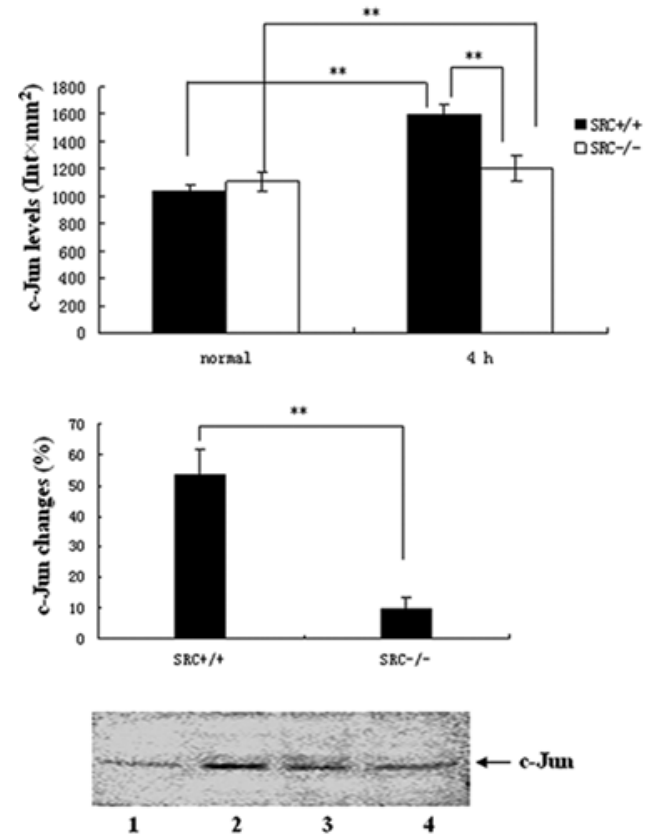

B
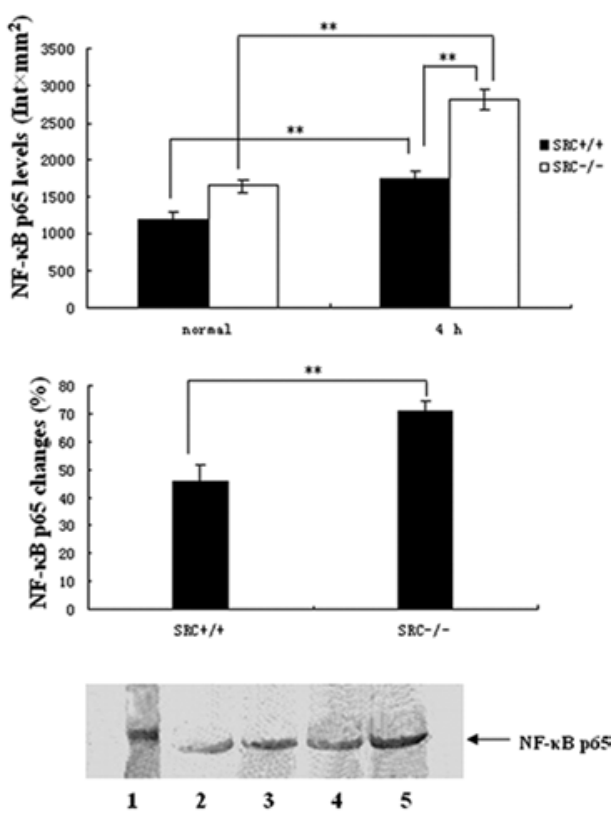

D
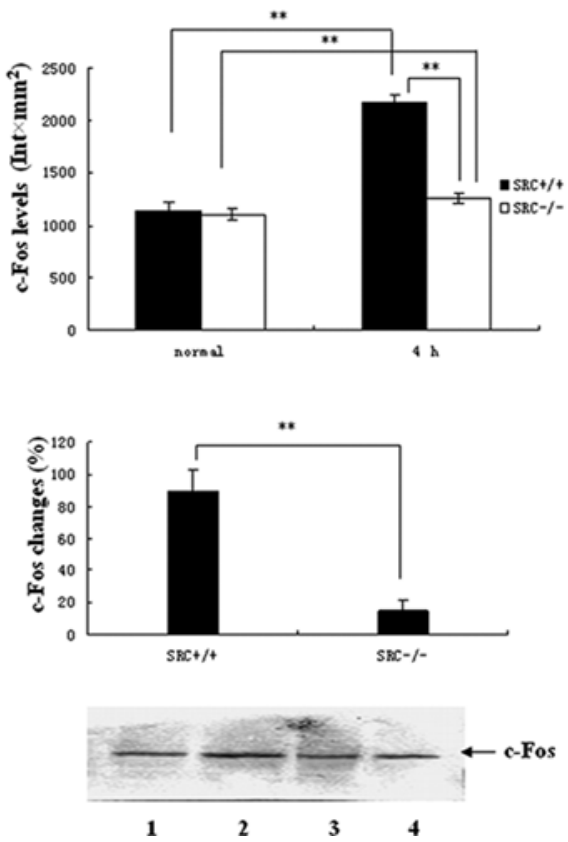

Figure 3. Protein expression analysis by Western blotting. (A-D) Protein expression of GR, NF-kB p65 and AP-1 (c-Jun and c-Fos) in PMs from SRC-3 ${ }^{+/+}$and SRC-3 $3^{--}$mice at $0 \mathrm{~h}$ (normal) and $4 \mathrm{~h}$ after injection of LPS (i.p., $5 \mathrm{mg} / \mathrm{kg}$ ), respectively. (A) Protein expression of GR in PM. Lane 1, 98-kDa marker; lanes 2 and 3, 0 and $4 \mathrm{~h}$ after injection of SRC- $3^{+/+}$mice; lanes 4 and 5, 0 and $4 \mathrm{~h}$ after injection of SRC-3 ${ }^{-/}$mice. (B) Protein expression of NF-kB p65 in PM. Lane 1 , 66-kDa marker; lanes 2 and 3, 0 and $4 \mathrm{~h}$ after injection of SRC- $3^{+/+}$mice; lanes 4 and 5, 0 and $4 \mathrm{~h}$ after injection of SRC- $3^{-/}$mice. (C) Protein expression of c-Jun in PM. Lanes 1 and 2, 0 and $4 \mathrm{~h}$ after injection of SRC- $3^{+++}$mice; lanes 3 and 4, 0 and $4 \mathrm{~h}$ after injection of SRC- $3^{-/}$mice. (D) Protein expression of c-Fos in PM. Lanes 1 and 2, 0 and $4 \mathrm{~h}$ after injection of SRC- $3^{+/+}$mice; lanes 3 and 4: 0 and $4 \mathrm{~h}$ after injection of SRC- $3^{-/}$mice. Data are expressed as the means \pm SEM per time point $(\mathrm{n}=5) .{ }^{* *} \mathrm{p}<0.01$.

macrophages and the synthesis of pro-inflammatory cytokines. Furthermore, SCR-3 deficiency suppressed the synthesis of pro-inflammatory cytokines and reduced the activity of PMs following stimulation by LPS. The synthesis and release of inflammatory cytokines from macrophages induced by LPS are essential for the natural immune response. The transcription of inflammatory cytokines may be suppressed by SCR-3 deficiency, showing that SCR-3 significantly affected the maintenance of normal natural immune response as well.
IL-10, also known as a cytokine synthesis inhibitory factor (CSIF), is mainly generated by $\mathrm{TH} 2$ cells and mononuclear macrophages. IL-10 suppresses the generation of cytokines (such as TNF- $\alpha$, IL-1 $\beta$, IL-6 and GM-CSF) from macrophages through the negative feedback regulation; therefore, the antiinflammatory effect is stimulated, and expression of several costimulatory molecules and MHC II molecules is downregulated; antigen presentation function of macrophages is accordingly suppressed (16). Therefore, over-release of TNF- $\alpha$ 
and severe disbalance of IL-10 may be a critical mechanism for the development of SIRS and resistance mechanism disorders. Our results showed that the expression of IL-10 mRNA in PMs from both SRC-3 $3^{+/+}$and SRC-3 ${ }^{-/}$mice was significantly elevated following treatment with LPS, and the elevated levels in the SRC- $-3^{-/}$mice were significantly higher compared to those of the SRC- $3^{+/+}$mice. The mechanism by which the expression of IL-10 mRNA was increased by SCR-3 deficiency may be related to the signaling pathway for regulating the expression of IL-10 and transcription factors.

Following treatment with LPS, TNF- $\alpha$ mRNA expression upon SCR-3 deficiency was suppressed, and the IL-10 mRNA expression was significantly higher. Our results showed that the balance between TNF- $\alpha$ and IL-10 was broken to some extent, and revealed that SRC-3 plays important roles not only in the regulation of synthesis of inflammatory cytokines in PMs, but also in maintaining the normal immune functions of PMs.

GR, NF- $\mathrm{kB}$ and AP-1 are known as important inflammatory transcription factors. They participate in the regulation of the body's immune response, and functional changes are related to the development of SIRS. The activities of these inflammatory transcription factors are related to the functional status of PMs, therefore, it is important for the clarification of the molecular mechanism involving the over-activation of PMs to study the effects of SCR-3 deficiency on transcription factors in PMs.

GC-GR reaction, an important stress and immune reaction, regulates the development of SIRS and possesses anti-inflammatory and immune suppressive effects; it also suppresses T-lymphocyte activation. GR can be treated as a ligand-dependent transcription factor, and GR can also regulate gene expression (17), suppression of T-cell activation and proliferation by GC, synthesis of cytokines and transactivation of some transcription factors in the process of T-cell activation (such as AP-1 and NF- $\mathrm{KB}$ ) through protein-protein interaction with other transcription factors $(18,19)$. The expression changes in the GR protein directly reflect the inflammatory reaction activity and immune status. Following LPS treatment, the decrease in the GR protein expression in the PMs of the SRC $-3^{--}$mice was significantly lower than that in the SRC $-3^{+/+}$ mice $(\mathrm{p}<0.01)$.

The results of our study showed that SCR-3 is associated with the inflammatory reaction activity of PMs, and SCR-3 deficiency induces the responsiveness of PMs to stimulation (such as LPS decrease), and even induces part of the PM immune function suppression. The AP-1 and NF- $\kappa \mathrm{B}$ inflammatory signal transduction pathways are the main links to the activation of the inflammatory cascade. GR interferes with the transcription activation of inflammatory cytokines through protein-protein interaction to suppress the synthesis and the release of inflammatory cytokines (20). The decline in the expression and function of GR in the PMs of SRC- $3^{+/+}$ mice relieved the suppression of GR on AP-1 and NF- $\mathrm{kB}$, and induced the over-activation of PMs. Furthermore, more inflammatory cytokines are released and SIRS is induced by the uncontrolled inflammatory reaction. However, the decrease in the GR protein expression in SRC-3/- mice was significantly lower compared to that in the SRC $-3^{+++}$mice. The results revealed that SCR-3 deficiency protects the function of GR and prevents the development of SIRS by restricting the extent of glucocorticoid resistance. In addition, the suppression of the immune function of PMs can be strengthened by SCR-3 deficiency. These results demonstrate that SCR-3 may be related to the co-activation of AP-1 and NF- $\mathrm{kB}$, and SCR-3 deficiency affects the expression and function changes of GR.

NF- $\mathrm{KB}$ specifically binds the $\mathrm{\kappa B}$ sites in the promoter or enhancer region of cytokines and adherence factors, which is necessary for the regulation of the immune response, inflammatory reaction, cell differentiation and development, cell adhesion and cell apoptosis, and initiates and regulates the transcription of these genes. Therefore, NF- $\mathrm{kB}$ plays important roles in the body's immune response, inflammatory reaction and cell differentiation and development (21). The p50/p65 heterodimer is the major component of intracellular NF- $\mathrm{KB}$ (22). In our study, the levels of NF- $\mathrm{BB}$ p65 protein expression in PMs of SRC- $3^{+/+}$mice were significantly higher than those of the SRC- $3^{-/-}$mice under normal conditions. In view of the importance of NF- $\mathrm{kB}$ in the process of the immune response, the results of our study showed that the relative lack of NF- $\mathrm{KB}$ expression was induced by SCR-3 deficiency; accordingly, immunosuppression of normal PMs was induced. SCR-3 is the co-activator of NF- $\mathrm{KB}$, and overexpression of SCR-3 significantly increases NF- $\kappa$ B transcription activity based on TNF- $\alpha$ induction, in a dose-dependent manner, and is critically involved in immune and inflammation reactions mediated by $\mathrm{NF}-\kappa \mathrm{B}$ (23). NF- $\kappa \mathrm{B}$ is an important transcription factor, and the increase in its expression and activity affects the function of GR through complex mechanisms, and decreases the biological effect of GR or even induces GCR. The presence of GCR in PMs from SRC- $3^{+/+}$mice promoted PMs to release abundant inflammatory cytokines, and the inflammatory cascade reaction was activated; accordingly, over-activation of PMs was induced through positive feedback reaction.

The over-activation of PMs is an important cause for resistance mechanism disorders in the body. The incidence and death rate of infection is increased due to immunosuppression following severe trauma, and the reason is the activation of cycloxygenase-2 (COX-2), which is induced by the activation of NF- $\mathrm{kB}$; then the production of PEG2 is increased. PEG2 is a powerful endogenous immunodepressant which suppresses the mitosis of T-cells, neutrophil chemotaxis and antibody synthesis of B-lymphocyte cells (24). Chen et al (25) showed that LPS induces the activation of NF- $\mathrm{\kappa B}$ and AP-1 through the activation of the p38 MAPK, and induces the release of NO and PEG2. However, the increase in NO and PEG2 induces the aggravation of inflammation and immune-reaction suppression, respectively.

Therefore, SCR-3 deficiency prevents the over-activation of PMs partly by suppressing the activity of NF- $\mathrm{kB}$. It appears that SCR-3 deficiency helps to prevent the occurrence of the immune function suppression of the body. However, NF- $\kappa \mathrm{B}$ plays an important role in the normal immune response of PMs, the severe regulation of NF- $\mathrm{BB}$ function induced by SCR-3 deficiency inevitable induced a partial loss of immune response function of PMs. Accordingly, resistance mechanism disorders will be induced or aggravated. The bidirectional effects of SCR-3 maintain the dynamic equilibrium between the inflammatory reaction and immune response of PMs.

AP-1 consists of the Fos/Jun heterodimer or Jun/Jun heterodimer, and the most common form of AP-1 is c-Jun/ 
c-Fos, which mediates cell proliferation, differentiation and expression of inflammatory cytokines. The inflammatory protein regulated by AP-1 also includes TNF- $\alpha$, IL-1, IL-6, IL-8, MIP-1 $\alpha$, MCP-1, ICAM-1, VCAM-1 and iNOS. AP-1 is an important transcription factor of the extracellular signalregulated kinase (ERK) pathway (26). ERK pathway is an important pathway related to cell proliferation and differentiation, which can be activated by inflammatory cytokines, such as IL-6 and TNF- $\alpha$.

Our study showed that the levels of c-Jun and c-Fos protein expression in PMs from the SRC- $3^{-/}$mice were not significant different from those of the SRC- $3^{+/+}$mice. However, c-Jun and c-Fos protein expression of PMs was increased at $4 \mathrm{~h}$ following stimulation with LPS. The MAPK pathway can be activated to different extents by LPS, and can induce an increase in c-Jun and c-Fos expression; then, AP-1 is activated. AP-1 regulates the transcription of abundant inflammatory cytokines; on the one hand, the increase in its activity promotes the release of inflammatory cytokines; on the other hand, the down-regulation of GR expression and function is induced by protein-protein interaction, and GCR and SIRS are induced. Subsequently, the over-activation and resistance mechanism disorders of PMs are induced. The results of our study showed that the increase in c-Jun and c-Fos expression in PMs in $\mathrm{SRC}-3^{-/-}$mice was significantly lower than that in SRC-3 $3^{+/+}$ mice $(\mathrm{p}<0.01)$. Therefore, SCR-3 deficiency partly suppresses the expression and activation of AP-1. LPS induces a large secretion of inflammatory cytokines, such as TNF- $\alpha$ and IL-1 $\beta$, and the synthesis and secretion of these inflammatory cytokines are related to the expression and activity of AP-1.

Previous studies have demonstrated that SCR-3 deficiency suppresses the transcriptional activation of inflammatory cytokines, such as TNF- $\alpha$ and IL- $1 \beta$, in PMs and decreases the synthesis and secretion of inflammatory cytokines induced by LPS. The suppression of the expression and activity of AP-1 is possible since the synthesis and secretion of inflammatory cytokines (such as TNF- $\alpha$ and IL-1 $\beta$ ) were relatively insufficient after SCR-3 deficiency. The activation of AP-1 could be suppressed to some extent by SCR-3 deficiency, and the overactivation of PMs is reduced. However, immune suppression of PMs may be induced based on the relative strengthening of GR's function. Accordingly, the regulation of SCR-3 in macrophages is extremely complex, and SCR-3 may play a key role in the inflammation and immune responses in macrophages.

\section{Acknowledgements}

This study was supported by the State Key Laboratory Open Foundation of Trauma, Burns and Combined Injury (no. SKLKF200910), and the China Postdoctoral Science Foundation (no. 20100471764).

\section{References}

1. Webster JC, Oakley RH, Jewell CM and Cidlowski JA Proinflammatory cytokines regulate human glucocorticoid receptor gene expression and lead to the accumulation of the dominant negative beta isoform: a mechanism for the generation of glucocorticoid resistance. Proc Natl Acad Sci USA 98: 6865-6870, 2001.
2. Goecke A and Guerrero J: Glucocorticoid receptor beta in acute and chronic inflammatory conditions: clinical implications. Immunobiology 211: 85-96, 2006.

3. Liao L, Kuang SQ, Yuan Y, Gonzalez SM, O'Malley BW and Xu J: Molecular structure and biological function of the canceramplified nuclear receptor coactivator SRC-3/AIB1. J Steroid Biochem Mol Biol 83: 3-14, 2002.

4. Gojis O, Rudraraju B, Alifrangis C, Krell J, Libalova P and Palmieri C: The role of steroid receptor coactivator-3 (SRC-3) in human malignant disease. Eur J Surg Oncol 36: 224-229, 2010.

5. Lydon JP and O'Malley BW: Minireview: steroid receptor coactivator-3: a multifarious coregulator in mammary gland metastasis. Endocrinology 152: 19-25, 2011.

6. Kurihara I, Shibata H, Suzuki T, et al: Transcriptional regulation of steroid receptor coactivator-1 (SRC-1) in glucocorticoid action. Endocr Res 26: 1033-1038, 2000.

7. Iwasaka $\mathrm{H}$ and Noguchi $\mathrm{T}$ : Th1/Th2 balance in systemic inflammatory response syndrome (SIRS). Nippon-Rinsho 62: 2237-2243, 2004 (In Japanese)

8. Rumbaugh KP, Colmer JA, Griswold JA and Hamood AN: The effects of infection of thermal injury by Pseudomonas aeruginosa $\mathrm{PAO}$ on the murine cytokine response. Cytokine 16: 160-168, 2001

9. Parihar A, Parihar MS, Milner S and Bhat S: Oxidative stress and anti-oxidative mobilization in burn injury. Burns 34: 6-17, 2008.

10. Li J, Su YP, Liu HN, Lou SF, Huang YS, Jiang JX and Wang JP: Diazepam-ketamine inhibits 3 kinds of serum inflammatory cytokines during the early stage in burned mice. Acta Academiae Medicinae Militaris Tertiae 26: 1-14, 2004.

11. Schwacha MG: Macrophages and post-burn immune dysfunction. Burns 29: 1-14, 2003.

12. Mackrell PJ, Daly JM, Mestre JR, et al: Elevated expression of cyclooxygenase-2 contributes to immune dysfunction in a murine model of trauma. Surgery 130: 826-833, 2001.

13. Deitch EA: Multiple organ failure. Pathophysiology and potential future therapy. Ann Surg 216: 117-134, 1992.

14. Du ZY and Su YP: Breeding, reproducing and identifying SRC-3 knock-out mice. Acta Academiae Medicinae Militaris Tertiae 27: 373-375, 2005 .

15. Sester DP, Trieu A, Brion K, et al: LPS regulates a set of genes in primary murine macrophages by antagonising CSF-1 action. Immunobiology 210: 97-107, 2005.

16. Gerard C, Bruyns C, Marchant A, et al: Interleukin 10 reduces the release of tumor necrosis factor and prevents lethality in experimental endotoxemia. J Exp Med 177: 547-550, 1993.

17. Auphan N, DiDonato JA, Rosette C, et al: Immunosuppression by glucocorticoids: inhibition of NF-kappa B activity through induction of I kappa B synthesis. Science 270: 286-290, 1995.

18. Riccardi C, Cifone MG and Migliorati G: Glucocorticoid hormone-induced modulation of gene expression and regulation of T-cell death: role of GITR and GILZ, two dexamethasoneinduced genes. Cell Death Differ 6: 1182-1189, 1999.

19. Scheinman RI, Cogswell PC, Lofquist AK and Baldwin AS Jr: Role of transcriptional activation of I kappa B alpha in mediation of immunosuppression by glucocorticoids. Science 270: 283-286, 1995.

20. Ogawa S, Lozach J, Benner C, et al: Molecular determinants of crosstalk between nuclear receptors and toll-like receptors. Cell 122: 707-721, 2005.

21. Wullaert A: Role of NF-kappaB activation in intestinal immune homeostasis. Int J Med Microbiol 300: 49-56, 2010.

22. Caradonna L, Mastronardi ML, Magrone T, et al: Biological and clinical significance of endotoxemia in the course of hepatitis $\mathrm{C}$ virus infection. Curr Pharm Des 8: 995-1005, 2002.

23. Werbajh S, Nojek I, Lanz R and Costas MA: RAC-3 is a NF-kappaB coactivator. FEBS Lett 485: 195-199, 2000.

24. Lo CJ, Cryer HG, Fu M and Lo FR: Regulation of macrophage eicosanoid generation is dependent on nuclear factor kappaB. J Trauma 45: 19-23, 1998

25. Chen C, Chen YH and Lin WW: Involvement of p38 mitogenactivated protein kinase in lipopolysaccharide-induced iNOS and COX-2 expression in J774 macrophages. Immunology 97: 124-129, 1999.

26. Sigal LH: Basic science for the clinician 43: the mitogenactivated protein kinase family in inflammatory signaling. J Clin Rheumatol 13: 96-99, 2007. 